\title{
Modelling the barriers of supply chain performance measurement in the Indian automotive industries
}

\author{
Department of Management Studies, \\ Indian Institute of Technology Roorkee, \\ Roorkee 247667, India \\ Email: rajesh_katiyar21@yahoo.co.in \\ Email: barua71@yahoo.co.in \\ *Corresponding author
}

Rajesh Katiyar* and Mukesh Kumar Barua

\begin{abstract}
The purpose of this paper is to explore the interactions among the imperative barriers of supply chain performance measurement (SCPM) system implementation in the Indian automotive companies. The Indian automotive companies have been facing various issues in implementation of SCPM system. We have used interpretive structural modelling (ISM) approach to investigate the interaction among different barriers in implementation of SCPM system in the Indian automotive industry. The results indicate that lack of awareness related to SCPM system and lack of top management dedication are the most significant barriers. On the other hand, disinclination of the support from distributors, dealers, retailers, lack of training manpower, and inefficient information technology system are the weak barriers. The results also reveal that there is a strong dependence among the barriers. Finally, various guidelines are provided for improving the performance and efficiency of the Indian automotive supply chains.
\end{abstract}

Keywords: supply chain; supply chain performance measurement; ISM; barriers; automotive industry.

Reference to this paper should be made as follows: Katiyar, R. and Barua, M.K. (2014) 'Modelling the barriers of supply chain performance measurement in the Indian automotive industries', Int. J. Intercultural Information Management, Vol. 4, No. 1, pp.51-66.

Biographical notes: Rajesh Katiyar is a Research Scholar of Department of Management Studies, IIT Roorkee. He is working on supply chain management. He is Master of Technology in Future Studies and Planning and Master of Science in Mathematics. He has published more than ten research papers in journals/conferences. He has recently won highly commended award for Emerald/Indian Academy of Management (IAM) South Asia Management Research Fund Award.

Mukesh Kumar Barua is Associate Professor in the Department of Management Studies, IIT Roorkee. His research area includes supply chain management, quality management, operations research, and operations management. He obtained Master of Technology in Mechanical Engineering and Doctor of Philosophy from IIT Madras. He has more than 15 years experience in teaching and research. He has published more than 40 research papers in reputed journals and conferences. 
This paper is a revised and expanded version of a paper entitled 'Modelling the barriers of supply chain performance measurement in Indian automotive industries' presented at the 'International Conference on Management and Business Innovation', MNIT Jaipur, India, 18-19 May 2013.

\section{Introduction}

In today's global business environment, supply chains (SC) not only include the manufacturer and suppliers, but also encompass distributors, warehouses, retailers, and even customers (Chopra and Meindl, 2001). SC is connected with two and/or more business parties by a flow of material, information, and funds. Nowadays, SC plays a very vital role in all business activities and particularly in manufacturing firms' effectiveness, efficiency, and better customer services. Gunasekaran et al. (2001) mentioned that Supply Chain Management (SCM) is a strategic decision for improving the firm's efficiency. Therefore, it is very crucial for all industries to put more focus on having a good SCM system. In today's context, measuring the performance of SC is very vital. Supply chain logistics performance was probably the initial attempt to define supply chain performance (Chow et al., 1994; Chia et al., 2009). Gunasekaran and Kobu (2007) stated that SCPM is very essential to measure the performance of a system. A unique attributes of SCPM is that it covers the entire SC that includes measuring interdependencies across the borders of a firm (Beamon, 1999; Gunasekaran et al., 2001; Gunasekaran et al., 2004; Shepherd and Gunter, 2006). It is very essential to develop an effective performance measurement system as it can facilitate a deeper understanding of SC and improve its overall performance (Austin, 1990; Chen and Paulraj, 2004; Sharma and Bhagwat, 2007). Though various industries are aware about different benefits of SCPM system many of them still lack in adopting an integrated system to improve the performance of SC. The Indian automotive companies lack in implementation of a proper system to improve the overall performance of SC. According to Saad and Patel (2006), lots of efforts have been made for SCPM at industry level. However, the success rate of implementing a performance measurement system is not very significant.

After globalisation, the Indian automotive sector has been flooded with investments from various global automotive manufacturers such as Honda, Ford, Toyota, etc. It has fuelled the competition among various manufacturer in terms of better product, cost, quality, delivery, flexibility, and customer satisfaction. According to Joshi et al. (2013), the Indian automotive sector is craving to increase their competitiveness in the global marketplace. Most of the global auto manufacturers are looking forward to make potential SC partner with the Indian automotive sector. Furthermore, the key factors of SC activities have become a matter of major concern to identify the importance of the automotive sector for national competitiveness, and these factors are known as performance indicators (Joshi et al., 2013). In order to outrival the aforementioned issues, companies are trying to improve the overall SCP. Currently, the Indian automotive sector is one of the fastest growing sectors of the global passenger vehicle markets and the second leading manufacturer of two wheelers. The automotive sector contributes more than $10 \%$ to the Indian GDP (Burange and Yamini, 2008; Automotive Mission Plan, 2006). 
In today's context, firms can compete in global market through better SCM system (Christopher and Towill, 2001; Charan et al., 2008). However, it's essential as well as a significant challenge before various firms to develop appropriate measures for SCPM (Gunasekaran and Kobu (2007). Since more than a decade, SCPM has been attracting the attention of the practitioners as well as academicians (Ganga and Carpinetti, 2011). Generally, firms face many obstacles in implementing a SCPM system and these obstacles are called as barriers, which not only create problems in operations process but also affect each others. Therefore, it is very important to first identify the barriers and then explore the relationships among these barriers. The top management of automotive industries needs to identify and focus on removing these barriers to make effective SC (Mudgal et al., 2010). Ganga and Carpinetti (2011) proposed a model to measure SCP based on causal relationships between metrics of the Supply Council Operations Reference (SCOR) model. They used fuzzy logic to predict performance based on performance metrics levels 1 and 2 of the SCOR model.

Many studies have been conducted from the global perspective on identifying the different barriers in automotive SCPM. However, there is a dearth of literature on identification of the barriers and that impact on performance measurement in automotive SCs from the Indian context. Charan et al. (2008) revealed that SCPM system helps companies to develop a long-term sustainable relationship between supply chain members. The better relationships among different members of SC also help in generating better strategies and opportunities. Charan et al. (2008) conducted a study from the Indian automotive industry perspectives to determine the key variable for SCPM system implementation and to improve the effectiveness and efficiency of SC. Recently, Joshi et al. (2013) examined the determinants of competitiveness for the Indian automotive component manufacturing industry, in special context to its SCP indicators. The both aforementioned studies have ignored the issue of identification of barriers in implementing SCPM system.

In this paper, we have made an attempt to fill this gap in the literature. We have employed the ISM approach to identify the inter-relationships between the key barriers of SCPM in the Indian automotive industry. Further, the barriers are categorised according to their dependence and driving power using cross-impact matrix multiplication applied to classification (MICMAC) approach.

The remainder of the paper is organised as follows. Section 2 discusses the identification of the barriers related to SCP. Section 3 demonstrates the relevant methodology. Section 4 discusses the MICMAC approach to understand the driving power and dependence of the barriers. The discussions and conclusions are provided in Section 5. Finally, the managerial implications and scope for future research are presented in Sections 6.

\section{Literature review}

SCPM reveals the effectiveness or competence of a SC system in any business process (Charan et al., 2008). In this section, depth review of the erstwhile relevant literature is provided. Detail discussion related to the different barriers of SCPM is given in following sub-sections. 


\subsection{Lack of awareness related to SCPM system (LARSCPMS)}

It is an important barrier in the Indian automotive industry and employees must be aware about SCPM system (Charan et al., 2009; Charan, 2012). In few sectors, it is found that most of the employees are not copiously aware how a system can perform better. Wang et al. (2008) mentioned that the employee awareness related to performance of any system is very crucial for all industries. However, employee awareness is not significant in various firms due to the short of appropriate laws, policies, and funding, etc. If employees are well informed about all these initiatives then they can perform better for their company. The lack of awareness is one the causes for performance measurement system failure, so it is one of the barriers that affect the firm's SCP.

\subsection{Inadequate strategic planning (ISP)}

It is another remarkable barrier in the Indian automotive sectors for SCPM. A better strategy increases company's performance and also identifies long-term strategy for managing the goals. Mudgal et al. (2010) showed that strategic planning provides a framework for making positive decision to evaluate performance ceaselessly. In current scenario, strategic planning needs more attention of the top management to remain competitive in market. Furthermore, the role of strategic planning is very essential to achieve any goal (Wang et al., 2008; Joshi et al., 2013).

\subsection{Lack of top management dedication (LTMD)}

It is one of the key barriers for any strategic plan and from decision perspectives (Hamel and Prahalad, 1989; Zhu and Sarkis, 2007). The involvement of the top management is very important for company's competitiveness in the market. The top management provides constantly support in strategic and action plans for effective implementing of SCPM (Ravi and Shankar, 2005). Mintzberg (1973) discussed that top management is very effective driving force for a company. Moreover, active contribution of the seniors is also one of the main success factors to improve the performance of any company (Berry and Rondinelli, 1998; Kuo et al., 2009). Therefore, top leaders and managers of a company play major role in all situations.

\subsection{Lack of trained manpower (LTM)}

It is another significant barrier in automotive industry. As various small manufacturing firms don't have much experienced manpower which can work efficiently and take responsibilities to handle different problems. According to Wang et al. (2008), the accessible manpower must be given repeated guidance to make sure that the latest tools/technologies are functioned. Training and education of workers are the major needs for measuring the effectiveness of supply chain in any organisation (Ravi and Shankar, 2005; Andrews-Speed, 2004). 


\subsection{Disinclination of the support from distributors, retailers, and dealers (DSDRD)}

It is another obstacle in the Indian automotive sector. Poor suppliers' commitment or lack of support from the distributors/dealers comes up with lower level of trust between traders. Suppliers must take this responsibility to deliver the consignment within the given lead time. Better supplier relationship leads to provide better product quality, delivery, flexibility, and minimum product cost. Furthermore, long-term partnership should be built with the all members of SC to improve overall SCP (Klassen and Vachon, 2003; Noci, 1997; Theyel, 2001; Vachon and Klassen, 2006). Lack of suppliers' support may also affect the overall performance of SC (Sarkar and Mohapatra, 2006; Meena et al., 2011; Meena and Sarmah, 2012; Meena and Sarmah, 2013; Meena and Sarmah, 2014).

\subsection{Inefficient information and technology system (IITS)}

It is a very important key barrier in the Indian automotive SC. It is one of the critical issues because most of the companies don't have efficient information and thus employees' are not aware about the various processes of SC. Therefore, efficient integration of information and technology in SC is very important (Wang et al., 2008). Resourceful information sharing through technology is very essential for improving the performance of SC (Luthra et al., 2011; Rogers and Tibben-Lembke, 1998). Resourceful information with good technology system is crucial for successful implementation of SCPM system.

\subsection{Lack of appropriate implementing SCP measurement system (LAISCPMS)}

It is the other barrier for SCPM in the Indian automotive sector. Gunasekaran et al. (2004) observed that SCPM initiative is the most suitable idea to implement. Additionally, Ren et al. (2004) also assured that implementation and appropriate use of SCPM system plays a significant role in SC profitability. The top-notch dimension is not about "how much you measure" but it's about "how well you measure" (Hofman, 2006). SCPM system helps all parties of SC and makes better contribution firms goals, and policies. The implementation of SCPM system requires high investment in the beginning.

\subsection{Lack of consistency in business capability between buyers and suppliers (LCBCBS)}

It is an extremely critical barrier in the Indian automotive firms. The miscommunication between buyers and suppliers affect the entire process of SC. Many companies are not prepared for consistency in business since they do not find remuneration for doing so (Wang et al., 2008). To practice it, companies must consider it as a hitch and to get relief from inconsistency in business. Informal relations and better communication help the companies to make better trading partners (Lin and Ho, 2008). Lack of trust or consistency between buyers and suppliers is a barrier in supply chain (Moberg et al., 2003; Sarkar and Mohapatra, 2006). 


\subsection{Lack of funding or financial constraints (LFFC)}

It is another crucial barrier in the Indian automotive SC. The cost or funding is a prime challenge to implement high technology/tools/equipment/machinery in any industry (Orsato, 2006; Walker et al., 2008; Wang et al., 2008). Financial support plays a vital role in purchasing any new technology or equipment for better implementation of SCPM system. Ravi and Shankar (2005) also emphasised that financial problem is one the major key obstacles in manufacturing firms because it requires more funds for product tracking, product recycling, operations process, and delivery systems.

\subsection{Destitute quality of human resource (DQHR)}

It is the fatal barrier in the Indian automotive industries (Perron, 2005; Mathiyazhagan et al., 2013). This problem can be removed by providing better training and education and also it helps in better implementation of SCMP system (Luthra et al., 2011). Better education and training will help the parent organisations to provide latest ideas for its employee. Lin and Ho (2008) mentioned that quality human resource injects fresh ideas in organisation and it empowers the manpower to decipher difficult problems.

\section{Research methodology}

This paper first identifies the different barriers and then explores their relationship with each others. A brainstorming sessions was conducted with 16 experts who are working at the managerial level in different Indian automotive firms. All the experts have more than ten years of experience in SCM area and the average age of all the experts is more than 40 years. Ten key barriers are identified related to implementation of SCPM system and then experts were asked to set up inter-relationship among these barriers.

Interpretive Structural Modelling (ISM) is a well-known method and has been successfully applied in different fields. ISM is basically based on transitivity and reachability concept (Raj et al., 2008). It helps to categorise various items and also to investigate inter-relationships among various items (Warfield, 1974; Sage, 1977). Saxena et al. (1992) applied ISM approach in the Indian cement industry to identify key variables and developed direct relationship among these variables. Ravi and Shankar (2005) utilised same technique in reverse logistics to analyse the interaction among the various barriers in reverse logistics. Recently, Charan et al. (2009) and Luthra et al. (2011) also used ISM technique in their study related to SCM system and green-SCM respectively. The aforementioned researchers have successfully applied the ISM technique to model and categorised those variables on their driving and dependence power. Therefore, it is a perfect technique to explore the impact of one barrier on other. Considering the relevance of ISM technique, we have used it here to investigate the inter-relationship among the barriers related to implementation of SCPM system in the Indian automotive sectors. The following steps are used similar to Ravi and Shankar (2005) and Mudgal et al. (2010) studies.

Step 1: A study of group problem-solving procedure is used for identification of the barriers related to the defined problem. After identifying the barriers, a contextual relationship is established among the barriers and a structural self-interaction matrix (SSIM) is developed. 
Step 2: After that, initial reachability matrix (IRM) is developed from the SSIM and the matrix is checked for transitivity to arrive at the final reachability matrix (FRM).

Step 3: The reachability matrix obtained in Step 2 is partitioned into different levels.

Step 4: Further, a conical matrix is development from the partitioned reachability matrix by clubbing the barriers together according to their level.

Step 5: Based on the relationship of reachability matrix, an ISM model is developed by replacing the barriers nodes with statements.

\subsection{Structural self-interaction matrix (SSIM)}

After identification of ten key barriers, the next step is to analyse these barriers. The contextual relationships among the barriers are achieved based on the experts' opinions called as brainstorming session. For analysing the interrelationships among these barriers, a contextual relationship of 'leads to' type is selected. It means, one barrier can improve another barrier. Four symbols are used to establish the contextual relationship among the barriers as given below. Table 1 is developed for the structural self-interaction matrix based on the contextual relationship.

$\mathrm{V}=$ If barrier $x$ influences barrier $y$

$\mathrm{A}=$ If barrier $x$ is influenced by barrier $y$

$\mathrm{X}=$ If barriers $x$ and $y$ influence each other

$\mathrm{O}=$ If barriers $x$ and $y$ do not influence each other

Table 1 Structural self-interaction matrix (SSIM)

\begin{tabular}{cccccccccccc}
\hline S. No. & Barriers & 10 & 9 & 8 & 7 & 6 & 5 & 4 & 3 & 2 & 1 \\
\hline 1 & LARSCPMS & V & V & V & V & V & V & V & V & V & V \\
2 & ISP & A & X & V & O & V & V & V & A & & \\
3 & LTMD & X & V & V & V & V & V & V & & & \\
4 & LTM & A & A & A & A & X & V & & & & \\
5 & DSDRD & A & A & A & A & A & & & & & \\
6 & IITS & A & A & A & A & & & & & \\
7 & LAISCPMS & A & A & A & & & & & & & \\
8 & LCBCBS & A & O & & & & & & & & \\
9 & LFFC & A & & & & & & & & & \\
10 & DQHR & & & & & & & & & & \\
\hline
\end{tabular}

\subsection{Development of the reachability matrix}

According to the model, the initial and final reachability matrices are to be developed from the SSIM. Therefore, SSIM needs to be transformed into binary digits (i.e., 1s or 0 s) called initial reachability matrix (IRM) which is shown in Table 2. Below given statements are followed in Table 1 to get IRM. 
- If $(x, y)$ entry in the SSIM is $\mathrm{V}$, in that case $(x, y)$ entry in the reachability matrix will be 1 and $(y, x)$ entry will be 0 .

- If $(x, y)$ entry in the SSIM is A, in that case $(x, y)$ entry in the reachability matrix will be 0 and $(y, x)$ entry will be 1 .

- If $(x, y)$ entry in the SSIM is X, in that case $(x, y)$ entry in the reachability matrix will be 1 and $(y, x)$ entry also will be 1 .

- If $(x, y)$ entry in the SSIM is $\mathrm{O}$, in that case $(x, y)$ entry in the reachability matrix will be 0 and $(y, x)$ entry also will be 0 .

Table 2 Initial reachability matrix (IRM)

\begin{tabular}{cccccccccccc}
\hline S. No. & Barriers & 1 & 2 & 3 & 4 & 5 & 6 & 7 & 8 & 9 & 10 \\
\hline 1 & LARSCPMS & 1 & 1 & 1 & 1 & 1 & 1 & 1 & 1 & 1 & 1 \\
2 & ISP & 0 & 1 & 0 & 1 & 1 & 1 & 0 & 1 & 1 & 0 \\
3 & LTMD & 0 & 1 & 1 & 1 & 1 & 1 & 1 & 1 & 1 & 1 \\
4 & LTM & 0 & 0 & 0 & 1 & 1 & 1 & 0 & 0 & 0 & 0 \\
5 & DSDRD & 0 & 0 & 0 & 0 & 1 & 0 & 0 & 0 & 0 & 0 \\
6 & IITS & 0 & 0 & 0 & 1 & 1 & 1 & 0 & 0 & 0 & 0 \\
7 & LAISCPMS & 0 & 0 & 0 & 1 & 1 & 1 & 1 & 0 & 0 & 0 \\
8 & LCBCBS & 0 & 0 & 0 & 1 & 1 & 1 & 1 & 1 & 0 & 0 \\
9 & LFFC & 0 & 1 & 0 & 1 & 1 & 1 & 1 & 0 & 1 & 0 \\
10 & DQHR & 0 & 1 & 1 & 1 & 1 & 1 & 1 & 1 & 1 & 1 \\
\hline
\end{tabular}

In the next step, the final reachability matrix (FRM) is obtained by incorporating the transitivity and few cells of the IRM are filled by inference. Since transitivity indicates the relationship of three elements, for example, if $x>y, y>z$ then $x>z$. After incorporating the transitivity theory in Table 2, the FRM is developed as shown in Table 3 . The dependence and driving power each barrier is also presented in Table 3.

Table 3 Final reachability matrix (FRM)

\begin{tabular}{ccccccccccccc}
\hline S. No & Barriers & 1 & 2 & 3 & 4 & 5 & 6 & 7 & 8 & 9 & 10 & Driving Power \\
\hline 1 & LARSCPMS & 1 & 1 & 1 & 1 & 1 & 1 & 1 & 1 & 1 & 1 & $\mathbf{1 0}$ \\
2 & ISP & 0 & 1 & 0 & 1 & 1 & 1 & 0 & 1 & 1 & 0 & $\mathbf{6}$ \\
3 & LTMD & 0 & 1 & 1 & 1 & 1 & 1 & 1 & 1 & 1 & 1 & $\mathbf{9}$ \\
4 & LTM & 0 & 0 & 0 & 1 & 1 & 1 & 0 & 0 & 0 & 0 & $\mathbf{3}$ \\
5 & DSDRD & 0 & 0 & 0 & 0 & 1 & 0 & 0 & 0 & 0 & 0 & $\mathbf{1}$ \\
6 & IITS & 0 & 0 & 0 & 1 & 1 & 1 & 0 & 0 & 0 & 0 & $\mathbf{3}$ \\
7 & LAISCPMS & 0 & 0 & 0 & 1 & 1 & 1 & 1 & 0 & 0 & 0 & $\mathbf{4}$ \\
8 & LCBCBS & 0 & 0 & 0 & 1 & 1 & 1 & 1 & 1 & 0 & 0 & $\mathbf{5}$ \\
9 & LFFC & 0 & 1 & 0 & 1 & 1 & 1 & 1 & $1 *$ & 1 & 0 & $\mathbf{7}$ \\
10 & DQHR & 0 & 1 & 1 & 1 & 1 & 1 & 1 & 1 & 1 & 1 & $\mathbf{9}$ \\
& Dependence & $\mathbf{1}$ & $\mathbf{5}$ & $\mathbf{3}$ & $\mathbf{9}$ & $\mathbf{1 0}$ & $\mathbf{9}$ & $\mathbf{6}$ & $\mathbf{6}$ & $\mathbf{5}$ & $\mathbf{3}$ & \\
\hline
\end{tabular}

Note:

*Shows the transitivity. 


\subsection{Level partitions}

After getting the FRM, partitions are made in order to find the hierarchy of barriers. The partitions are performed using Tables 4-5. The reachability and antecedent set for each barrier is obtained from the final reachability matrix (Warfield, 1974). The reachability set includes the barrier itself and others which it may help to achieve, and the antecedent set consists of itself and the other barriers which helps in achieving it. Later, intersection set is derived for the each barrier. The intersection set of the each barrier is found from the intersection of its reachability and antecedent set. Further, top most priority is assigned for that barrier whose membership in reachability and the intersection are the same and the barrier is expelled from the following iteration, likewise procedure leads to the last iteration leading to the lowest level. First iteration is shown in Table 4; whereas the disinclination of the support from the distributors, retailers and dealers (Barrier 5) is found at level I. Similarly, iterations are repeated till the level of each barrier is achieved. Table 5 summarises the results for iterations ii-vii.

Table 4 Iteration $\mathrm{i}$

\begin{tabular}{ccccc}
\hline Barriers & Reachability Set & Antecedents Set & Intersection Set & Level \\
\hline 1 & $1,2,3,4,5,6,7,8,9,10$ & 1 & 1 & \\
2 & $2,4,5,6,8,9$ & $1,2,3,9,10$ & 2,9 & \\
3 & $2,3,4,5,6,7,8,9,10$ & $1,3,10$ & 3,10 & \\
4 & $4,5,6$ & $1,2,3,4,6,7,8,9,10$ & 4,6 & \\
5 & 5 & $1,2,3,4,5,6,7,8,9,10$ & 5 & I \\
6 & $4,5,6$ & $1,2,3,4,6,7,8,9,10$ & 4,6 & \\
7 & $4,5,6,7$ & $1,3,7,8,9,10$ & 7 & \\
8 & $4,5,6,7,8$ & $1,2,3,8,9,10$ & 8 & \\
9 & $2,4,5,6,7,8,9$ & $1,2,3,9,10$ & 2,9 & \\
10 & $2,3,4,5,6,7,8,9,10$ & $1,3,10$ & 3,10 & \\
\hline
\end{tabular}

Table 5 Iteration ii-vii

\begin{tabular}{cccccc}
\hline Iteration & Barriers & Reachability Set & Antecedents Set & Intersection Set & Level \\
\hline$i i$ & 4 & 4,6 & $1,2,3,4,6,7,8,9,10$ & 4,6 & II \\
$i i$ & 6 & 4,6 & $1,2,3,4,6,7,8,9,10$ & 4,6 & II \\
$i i i$ & 7 & 7 & $1,3,7,8,9,10$ & 7 & III \\
$i v$ & 8 & 8 & $1,2,3,8,9,10$ & 8 & IV \\
$v$ & 2 & 2,9 & $1,2,3,9,10$ & 2,9 & V \\
$v$ & 9 & 2,9 & $1,2,3,9,10$ & 2,9 & V \\
$v i$ & 3 & 3,10 & $1,3,10$ & 3,10 & VI \\
$v i$ & 10 & 3,10 & $1,3,10$ & 3,10 & VI \\
$v i i$ & 1 & 1 & 1 & 1 & VII \\
\hline
\end{tabular}




\subsection{Development of conical matrix}

Development of the conical matrix is acquired from the partitioned reachability matrix by clubbing the barriers together according to their level across the column and rows of the final reachability matrix which is used for developing the final diagraph and later on structural model. As an example, the barrier 5 is found at level I, whereas the barriers 4 and 6 are at level II. Correspondingly, all the barriers are clubbed as per their level partition (see Tables 4-5). Furthermore, the dependence power of a barrier is calculated by summing up the number of $1 \mathrm{~s}$ in the columns and the driving power is calculated by summing up the number of $1 \mathrm{~s}$ in the rows. Finally, conical matrix is shown in Table 6.

Table 6 Conical matrix

\begin{tabular}{cccccccccccc}
\hline Barriers $S . N o$. & 5 & 4 & 6 & 7 & 8 & 2 & 9 & 10 & 3 & 1 & Driving Power \\
\hline DSDRD & 1 & 0 & 0 & 0 & 0 & 0 & 0 & 0 & 0 & 0 & $\mathbf{1}$ \\
LTM & 1 & 1 & 1 & 0 & 0 & 0 & 0 & 0 & 0 & 0 & $\mathbf{3}$ \\
IITS & 1 & 1 & 1 & 0 & 0 & 0 & 0 & 0 & 0 & 0 & $\mathbf{3}$ \\
LAISCPMS & 1 & 1 & 1 & 1 & 0 & 0 & 0 & 0 & 0 & 0 & $\mathbf{4}$ \\
LCBCBS & 1 & 1 & 1 & 1 & 1 & 0 & 0 & 0 & 0 & 0 & $\mathbf{5}$ \\
ISP & 1 & 1 & 1 & 0 & 1 & 1 & 1 & 0 & 0 & 0 & $\mathbf{6}$ \\
LFFC & 1 & 1 & 1 & 1 & 1 & 1 & 1 & 0 & 0 & 0 & $\mathbf{7}$ \\
DQHR & 1 & 1 & 1 & 1 & 1 & 1 & 1 & 1 & 1 & 0 & $\mathbf{9}$ \\
LTMD & 1 & 1 & 1 & 1 & 1 & 1 & 1 & 1 & 1 & 0 & $\mathbf{9}$ \\
LARSCPMS & 1 & 1 & 1 & 1 & 1 & 1 & 1 & 1 & 1 & 1 & $\mathbf{1 0}$ \\
Dependence & $\mathbf{1 0}$ & $\mathbf{9}$ & $\mathbf{9}$ & $\mathbf{6}$ & $\mathbf{6}$ & $\mathbf{5}$ & $\mathbf{5}$ & $\mathbf{3}$ & $\mathbf{3}$ & $\mathbf{1}$ & \\
\hline
\end{tabular}

\subsection{Building the ISM-based model}

Next, the ISM-based model is developed on the basis of the final reachability matrix. It exposes the relationship between the two barriers which are shown by an arrow from one barrier to another barrier. If the barrier $x$ acts on the barrier $y$, an arrow will be used to point from $x$ to $y$. After removing the transitivity's as explained in the ISM technique, an ISM model is prepared as shown in Figure 1. It can be seen in Figure 1 that the lack of awareness related to SCPM system (Barrier 1) is the most crucial barrier for better implementation of the SCPM system in the Indian automotive sectors. Disinclination of the support from the distributors, retailers and dealers (Barrier 5) is shown at the peak of the model and it means that this barrier will influence the entire process of SC.

The lack of awareness related to the implementation of SCPM system (Barrier 1) leads to the lack of top management dedication (Barrier 3) and destitute quality of human resource (Barrier 10) towards the upgrading of SCP. Lack of the top management dedication (Barrier 3) and destitute quality of human resource (Barrier 10) are interrelated and should be in positioned before assigning inadequate strategic planning (Barrier 2) and financial constraints (Barrier 9), which would be counter of implementing the SCMP system. Similarly, inadequate strategic planning (Barrier 2) and lack of funding or financial constraints (Barrier 9) are also the interrelated barriers and lead to the lack of consistency in business capability between buyers and suppliers (Barrier 8). The barrier (8) will also help in lack of appropriateness in implementing SCPM system 
(Barrier 7). Furthermore, this (Barrier 7) leads to lack of training manpower (Barrier 4) and inefficient information and technology system (Barrier 6). The barriers (4 and 6) guide to the disinclination of the support from the distributors, retailers and dealers (Barrier 5). The supports of suppliers or distributors are very essential to make effective and efficient SC. Moreover, without the support of all bottom side of the barriers, it would be very difficult to fill all the gaps of SC process.

Figure 1 ISM model for Indian automotive supply chain barriers

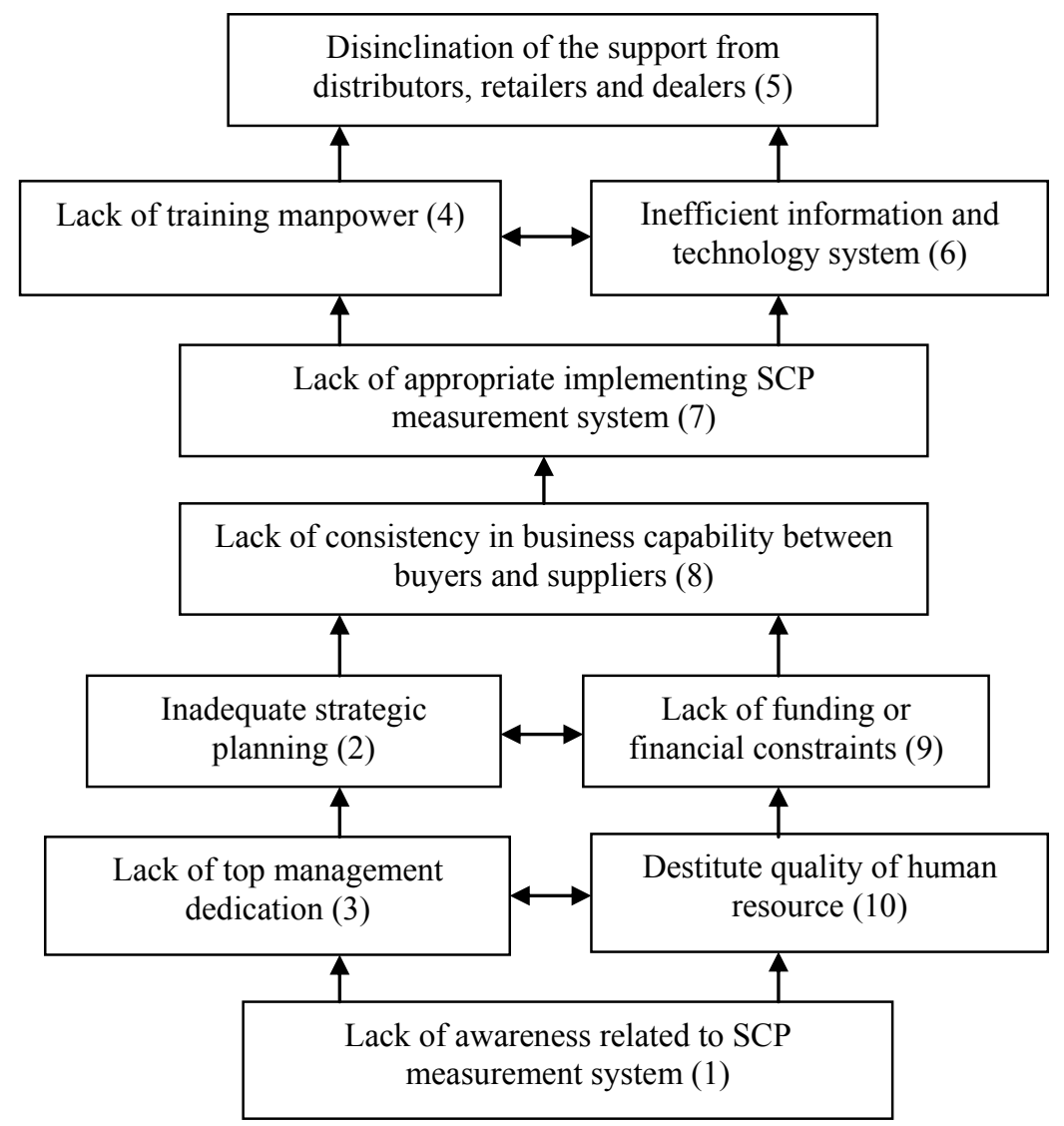

\section{MICMAC analysis}

MICMAC method was developed by Duperrin and Godet (1973) to study diffusion of impacts through the reaction paths and loops for developing a hierarchy for the variables and can be used to identify the elements in a complicated system. According to Mandal and Deshmukh (1994), MICMAC analysis analyses the dependence and driving power of the barriers. In MICMAC analysis, all the barriers are clustered into four co-ordinates according to their categories of autonomous, dependence, linkage and the driver barriers. Classification of the barriers is shown in Figure 2. The first cluster comprises the barriers 
that have weak dependence and driving power. The second cluster portrays the dependent barriers that have strong dependence with weak driving power. The third cluster contains those barriers that have strong dependence and driving power. The fourth cluster includes those barriers that have weak dependence and strong driving power.

Figure 2 Dependence power and driving power diagram (see online version for colours)

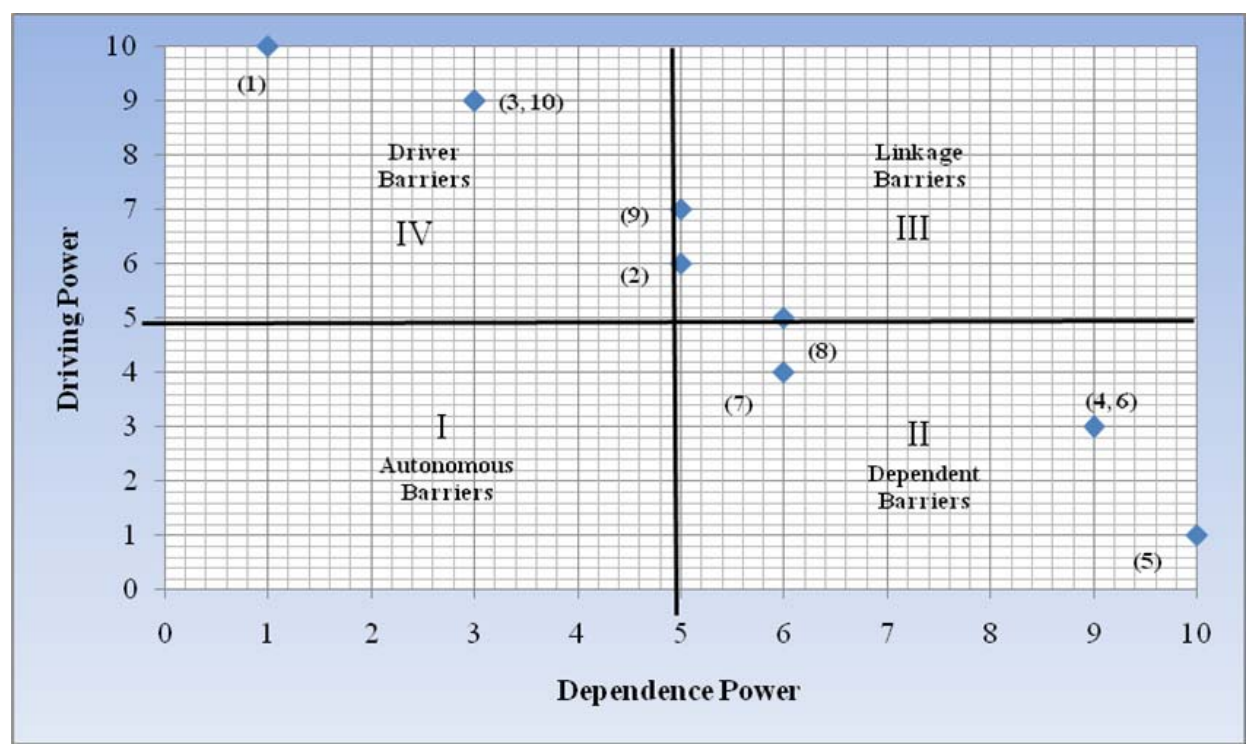

\section{Discussions and conclusions}

Some key measures of SCPM are considered to be very essential in in different SC processes and also considered as significant challenges for managers in different organisations. However, there are always few hidden barriers in the SCs of all organisations. The key barriers need to be explored for the success and efficiency of any SCs. Therefore, this paper makes an attempt to identify these key barriers in implementation of SCPM system in the Indian Automotive industry and also explored the inter-relationships among these barriers. We have utilised ISM technique for categorising the barriers and also to explore their inter-relationships. Figure 2 provides very valuable suggestions about the impact of these barriers on the implementation of SCPM system.

The results provide better approach for the top managers of the organisations to think about these barriers in their SC. It is observed from the Figure 1 that the lack of awareness related to the implementation of SCPM system (Barrier 1) is one of the major barriers which is placed at the base of the hierarchy. Consequently, the firms' management must focus on this barrier to make their SC more effective. Figure 2 shows that there is no independent or autonomous barrier which means that the all considered barriers influence the implementation of the SCPM system in the Indian automotive industry. 
It is also found that the disinclination of the support from the distributors, retailers, and dealers (Barrier 5), lack of training manpower (Barrier 4), inefficient information and technology system (Barrier 6), lack of appropriate implementing SCP measurement system (Barrier 7), and lack of consistency in business capability between buyers, and suppliers (Barrier 8) are the weak driver barriers. Nevertheless, these have strong dependence on the other barriers, for example, inadequate strategic planning (Barrier 2), lack of funding or financial constraints (Barrier 9), destitute quality of human resource (Barrier 10), lack of top management dedication (Barrier 3), and lack of awareness related to SCPM system (Barrier 1). Further, it is also observed from the Figure 2 that there is no linkage barrier. Only five barriers are in the fourth co-ordinate (driver barriers). Hence, these barriers are the root barriers and the firms' top management need to put more focus on these barriers as an idea to get success. These results may be very helpful for the top management in automotive industries related to identification of the significant barriers that impact the overall performance of SC.

\section{Managerial implications and scope for the future research}

In this paper, an ISM based model is developed to identify the significant barriers for implementing the SCPM system in the Indian automotive industry. The identified barriers of automotive SC are very important in the entire process SC for the top management of the companies. The model developed here is helpful for the organisations which are working in the automotive sector for implementing an effective SCPM system. The barriers which are more crucial are called as driving barriers. It means firm's managers must give more focus on these barriers and should take initiative to eradicate these barriers.

For example, the barriers $(1,2,3,9$ and 10) given in the fourth co-ordinate of Figure 2 are the top root barriers. Therefore, more attention on such barriers can help the organisations to be achieving high overall SCP. On the other hand, the few barriers are found to have more dependencies on the other barriers. It suggests that these barriers have less driving power in the implementation of SCPM system. Therefore, these barriers don't need much attention from the managers. Moreover, there are also few barriers that don't affect the SCP. This paper provides various guidelines and strategies for the managers of the automotive industries to improve the performance of their SC.

The theoretical model developed here is limited to identification of the barriers in the implementation of SCPM in the Indian automotive industries. Similar study can be carried out in different sectors as well from different perspectives.

Moreover, the model proposed here has not been validated statistically. The model can be tested in the future using structural equation modelling (a well-known linear structural relationship approach) technique, as it has the potential of testing the validity of such type of models as discussed by Jharkharia and Shankar (2005). The research conducted in this paper is predominantly focused on the Indian automotive industry. However, a similar study can be conducted for the other industries in order to verify the applicability of the proposed model. In future, other techniques such as analytical hierarchy process (AHP) or integrated Fuzzy-AHP can also be utilised for the comparison purpose. 


\section{References}

Andrews-Speed, P. (2004) 'Energy policy and regulation in the People's Republic of China', Kluwer Law International, The Hague/London/New York.

Austin, J.E. (1990) Managing in Developing Countries, Free Press, New York, NY.

Automotive Mission Plan 2006-2016 (2006) Automotive Mission Plan 2006-2016, Ministry of Heavy Industries \& Public Enterprises, Government of India, New Delhi.

Beamon, B.M. (1999) 'Measuring supply chain performance', International Journal of Operations \& Production Management, Vol. 19, No. 3, pp.275-292.

Berry, M.A. and Rondinelli, D.A. (1998) 'Proactive corporate environmental management: a new industrial revolution', Academy of Management Executive, Vol. 12, No. 2, pp.38-50.

Burange, L.G. and Yamini, S. (2008) Competitiveness of firms in Indian automobile industry, Working Paper UDE (CAS) 23/(8)/1/2008

Charan, P. (2012) 'Supply chain performance issues in an automobile company: a SAP-LAP analysis', Measuring Business Excellence, Vol. 16, No. 1, pp.67-86.

Charan, P., Shankar, R. and Baisya, R.K. (2008) 'Analysis of interactions among the variables of supply chain performance measurement system implementation', Business Process Management Journal, Vol. 14, No. 4, pp.512-529.

Charan, P., Shankar, R. and Baisya, R.K. (2009) 'Modelling the barriers of supply chain performance measurement system implementation in the Indian automobile supply chain', International Journal of Logistics Systems and Management, Vol. 5, No. 6, pp.614-630.

Chen, I.J. and Paulraj, A. (2004) 'Towards a theory of supply chain management: the constructs and measurements', Journal of Operations Management, Vol. 22, No. 2, pp.119-150.

Chia, A., Goh, M. and Hum, S.H. (2009) 'Performance measurement in supply chain entities: balanced scorecard perspective', Benchmarking: An International Journal, Vol. 16, No. 5, pp.605-620.

Chopra, S. and Meindl, P. (2001) Supply Chain Management: Strategy, Planning, and Operations, Prentice-Hall, New Jersey.

Chow, G., Heaver, T.D. and Henriksson, L.E. (1994) 'Logistics performance: definition and measurement', International Journal of Physical Distribution \& Logistics Management, Vol. 24, No. 1, pp.17-28.

Christopher, M. and Towill, D.R. (2001) 'An integrated model for the design of agile supply chains', International Journal of Physical Distribution and Logistics Management, Vol. 31, No. 4, pp.235-246.

Duperrin, J.C. and Godet, M. (1973) Methode de Hierarhisation des Elements d'un Systeme Economique du, CEA, R-45-51, Paris.

Ganga, G.M.D. and Carpinetti, L.C.R. (2011) 'A fuzzy logic approach to supply chain performance management', International Journal of Production Economics, Vol. 134, pp.177-187.

Gunasekaran, A. and Kobu, B. (2007) 'Performance measures and metrics in logistics and supply chain management: a review of recent literature (1995-2004) for research and applications', International Journal of Production Research, Vol. 45, No. 12, pp.2819-2840.

Gunasekaran, A., Patel, C. and McGaughey, R.E. (2004) 'A framework for supply chain performance measurement', International Journal of Production Economics, Vol. 87, pp.333-347.

Gunasekaran, A., Patel, C. and Tirtiroglu, E. (2001) 'Performance measures and metrics in a supply chain environment', International Journal of Operations and Production Management, Vol. 21, Nos. 1/2, pp.71-87.

Hamel, G. and Prahalad, C.K. (1989) 'Strategic intent', Harvard Business Review, Vol. 67, pp.63-76.

Hofman, D. (2006) 'Getting to world-class supply chain measurement', Supply Chain Management Review, October, pp.18-24. 
Jharkharia, S. and Shankar, R. (2005) 'IT-enablement of supply chains: understanding the barriers', The Journal of Enterprise Information Management, Vol. 18, No. 1, pp.11-27.

Joshi, D., Nepal, B., Rathore, A.P.S. and Sharma, D. (2013) 'On supply chain competitiveness of Indian automotive component manufacturing industry', International Journal of Production Economics, Vol. 143, No. 1, pp.151-161.

Klassen, R.D. and Vachon, S. (2003) 'Collaboration and evaluation in the supply chain: the impact on plant-level environmental investment', Production and Operations Management, Vol. 12, No. 3, pp.336-352.

Kuo, T.C., Ma, H.Y., Huang, S.H., Hu, A.H. and Huang, C.S. (2009) 'Barrier analysis for product service system using interpretive structural model', The International Journal of Advanced Manufacturing Technology, Vol. 49, Nos. 1-4, pp.407-417.

Lin, C-Y. and Ho, Y-H. (2008) 'An empirical study on logistics services providers' intention to adopt green innovations', Journal of Technology, Management and Innovation, Vol. 3, No. 1, pp.17-26.

Luthra, S., Kumar, V., Kumar, S. and Haleem, A. (2011) 'Barriers to implement green supply chain management in automobile industry using interpretive structural modeling technique - an Indian perspective', Journal of Industrial Engineering and Management, Vol. 4, No. 2, pp.231-257.

Mandal, A. and Deshmukh, S.G. (1994) 'Vendor selection using interpretive structural modelling (ISM)', International Journal of Operations and Production Management, Vol. 14, No. 6, pp.52-59.

Mathiyazhagan, K., Govindan, K., NoorulHaq, A. and Geng, Y. (2013) 'An ISM approach for the barrier analysis in implementing green supply chain management', Journal of Cleaner Production, Vol. 47, pp.283-297.

Meena, P.L. and Sarmah, S.P. (2012) 'Development of a supplier satisfaction index model', Industrial Management \& Data Systems, Vol. 112, No. 8, pp.1236-1254.

Meena, P.L. and Sarmah, S.P. (2013) 'Multiple sourcing under supplier failure risk and quantity discount: a genetic algorithm approach', Transportation Research Part E, Vol. 50, No. 1, pp.84-97.

Meena, P.L. and Sarmah, S.P. (2014) 'Mitigating the risks of supply disruption under stochastic demand', International Journal of Management Science and Engineering Management, Vol. 9, No. 3, pp.157-168.

Meena, P.L., Sarmah, S.P. and Sarkar, A. (2011) 'Sourcing decisions under risks of catastrophic event disruptions', Transportation Research Part E, Vol. 47, pp.1058-1074.

Mintzberg, H. (1973) The Nature of Managerial Work, Harper and Row, New York.

Moberg, C.R., Speh, T.W. and Freese, T. (2003) 'SCM: making the vision a reality', Supply Chain Management Review, September-October, pp.34-39.

Mudgal, R.K., Shankar, R., Talib, P. and Raj, T. (2010) 'Modelling the barriers of green supply chain practices: an Indian perspective', International Journal of. Logistics Systems and Management, Vol. 7, No. 1, pp.81-107.

Noci, G. (1997) 'Designing "green" vendor rating systems for the assessment of a supplier's environmental performance', European Journal of Purchasing and Supply Management, Vol. 3, No. 2, pp.103-114.

Orsato, R. (2006) 'Competitive environmental strategies: when does it pay to be green?', California Management Review, Vol. 48, No. 2, pp.127-143.

Perron, G.M. (2005) Barriers to Environmental Performance Improvements in Canadian SMEs, Dalhousie University, Canada.

Raj, T., Shankar, R. and Suhaib, M. (2008) 'An ISM approach for modelling the barriers of flexible manufacturing system: the case for India', International Journal of Production Research, Vol. 46, No. 24, pp.6883-6912. 
Ravi, V. and Shankar, R. (2005) 'Analysis of interactions among the barriers of reverse logistics', Technological Forecasting and Social Change, Vol. 72, No. 8, pp.1011-1029.

Ren, C., Chai, Y. and Liu, Y. (2004) 'Active performance management in supply chains', IEEE International Conference on Systems, Man and Cybernetics, Vol. 7, pp.6036-6041.

Rogers, D.S. and Tibben-Lembke, R.S. (1998) Going Backwards: Reverse Logistics Trends and Practices, Reverse Logistics Executive Council, Pittsburgh, PA.

Saad, M. and Patel, B. (2006) 'An investigation of supply chain performance measurement in the Indian automotive sector', Benchmarking: An International Journal, Vol. 13, Nos. 1/2, pp.36-53.

Sage, A.P. (1977) Interpretive Structural Modeling: Methodology for Large-Scale Systems, McGraw-Hill, New York, USA, pp.91-164.

Sarkar, A. and Mohapatra, P.K.J. (2006) 'Evaluation of supplier capability and performance: a method for supply base reduction', Journal of Purchasing and Supply Management, Vol. 12, pp.148-163.

Saxena, J.P., Sushil and Vrat, P. (1992) 'Scenario building: a critical study of energy conservation in the Indian cement industry', Technological Forecasting and Social Change, Vol. 41, No. 2, pp.121-146.

Sharma, M.K. and Bhagwat, R. (2007) 'An integrated BSC-AHP approach for supply chain management evaluation', Measuring Business Excellence, Vol. 11, No. 3, pp.57-68.

Shepherd, C. and Gunter, H. (2006) 'Measuring supply chain performance: current research and future directions', International Journal of Productivity and Performance Management, Vol. 55, Nos. 3/4, pp.242-258.

Theyel, G. (2001) 'Customer and supplier relations for environmental performance', Greener Management International, Vol. 35, pp.61-69.

Vachon, S. and Klassen, R. (2006) 'Extending green practices across the supply chain: the impact of upstream and downstream integration', International Journal of Operations and Production Management, Vol. 26, No. 7, pp.795-821.

Walker, H., Sisto, L.D. and McBrain, D. (2008) 'Drivers and barriers to environmental supply chain management practices: lessons from the public and private sectors', Journal of Purchasing and Supply Management, Vol. 14, pp.69-85.

Wang, G., Wang, Y. and Zhao, T. (2008) 'Analysis of interactions among the barriers to energy saving in China', Energy Policy, Vol. 36, pp.1879-1889.

Warfield, J.N. (1974) 'Developing interconnection matrices in structural modeling', IEEE Transactions on Systems on Man, and Cybernetics, Vol. 4, No. 1, pp.51-81.

Zhu, Q. and Sarkis, J. (2007) 'The moderating effects of institutional pressures on emergent green supply chain practices and performance', International Journal of Production Research, Vol. 45, Nos. 18/19, pp.4333-4355. 